\title{
The drivers of energy-related financial hardship in Australia - understanding the role of income, consumption and housing
}

\author{
Saunders and Bedford (2017) demonstrated that income levels are inadequate for some \\ Australian households to maintain a basic standard of living. Analysing utility bills can \\ extend this consideration of income adequacy issues given the essential nature of services \\ such as electricity, telephony and water. This article builds on the work presented by \\ Simshauser and Nelson (2014) about key demographic cohorts in Australia that have a \\ high incidence of energy-related financial hardship. Our analysis indicates that energy \\ related financial hardship is likely to be related to a combination of the following: family \\ formation demographics; low-income (often reliant upon government income support); \\ higher household size; and higher than average consumption. Our policy \\ recommendations are relatively straightforward: development of tools to allow easier \\ 'shopping around' by energy customers; cessation of credit-checking by energy retailers \\ as a means of restricting access to energy offers; reform of state-based concessions \\ frameworks; a lifting of income support for some key cohorts (e.g. unemployed); \\ improvements to energy-efficiency standards; and amendments to tenancy laws to \\ overcome potential principal-agent issues associated with uptake of new products and \\ services such as embedded solar PV and battery storage.
}

Keywords: energy; inequality; income adequacy

JEL Codes: D04, D47, Q40, Q41, Q48

\section{Introduction}

Over the last decade the price of electricity in Australia has increased at an annual growth rate of

8 percent, more than twice that of wages growth $(3.1 \%)$ and nearly four times higher than

inflation $(2.4 \%)$ (ACCC, 2017). These increases have been driven predominantly by higher

network costs but wholesale prices and other costs have also contributed (see ACCC, 2017; and

Orton and Nelson, 2015). 
There has been a sharp focus on the efficiency and fairness of the Australian retail market for electricity. The Commonwealth Government has commissioned a review of retail electricity markets by the Australian Competition and Consumer Commission which is due to report its findings in 2018 (ACCC, 2017). The Victorian Government also initiated a review chaired by the former Deputy Premier, John Thwaites that made several recommendations in 2017 (DELWP, 2017). Prominent 'think-tanks' have questioned the market's operation (see Grattan Institute, 2017, as an example). On the other hand, Nelson et al (2018) demonstrate that Australian electricity markets are providing price dispersion which is welfare enhancing. ${ }^{1}$ Importantly, Australia has amongst the highest uptake of household distributed solar PV generation of anywhere in the world and is expected to be among the leading markets for deployment of battery storage (see Orton et al, 2017). The high utilisation of embedded solar has led to further discussion about customer equity as reduced demand from the grid results in fixed costs being disproportionately apportioned to those without solar PV.

But the question of energy affordability is not limited to a consideration of price. It has broader context. Social safety nets such as government income support (e.g. unemployment allowances) and their interaction with wages needs to be considered alongside broader living costs to determine if an adequate standard of living, that includes access to essential services such as energy, can be maintained. The energy efficiency rating of a home and the ability to improve this rating through capital upgrades and appliance replacements are also important factors that determine the cost of energy (Chester, 2014).

Increases in energy prices have occurred against a backdrop of an emerging debate within Australia about income and wealth equality. While much of the debate is focused on broader issues, specific studies have considered the adequacy of income support for low-income households. Saunders and Bedford (2017) utilised a 'budget standard' for various households to demonstrate the inadequacy of government income support for some demographic cohorts. 
The purpose of this article is to consider the relationship between income, income support, home ownership and housing affordability and energy-related financial hardship ${ }^{2}$. Acknowledging the ongoing debate around the efficiency and equity of retail electricity markets, our focus is on consideration of the other material non-price drivers of energy related financial hardship. We have sourced data on hardship customers from AGL Energy Ltd, one of the largest electricity and gas retailers in Australia's east-coast National Electricity Market (NEM). Section 2 provides a literature review of both broader issues relating to income and wealth inequality, as well as specific research on these issues as they relate to energy. Our method of analysis is documented in Section 3 and the presentation of results is in Section 4.. Policy recommendations and discussion is contained in Section 5 with brief concluding remarks following in Section 6.

\section{An overview of the literature relating to financial inequality and energy}

Analysis has shown that increasing inequality of wealth and disposable income tends to limit economic growth and may impact on social cohesion (OECD, 2015; Lee and Son, 2016; ACOSS, 2015). The importance of income in managing day-to-day household budgets is clear, but the distribution and accumulation of wealth (which considers a person's stock of assets and savings) is arguably even more critical to questions of personal wellbeing and the health of the economy more broadly. ACOSS (2015) attributes this to the fact that a concentration of resources means that relatively fewer people are able to contribute economically with low rates of participation in activities such as starting a business, buying a house, or purchasing goods and services. As a result, more people are reliant on government interventions. If these interventions are inadequate to achieve a minimum standard of healthy living, then household budgets are unlikely to be sustainable. 
Despite the heavy influence of income and housing conditions on the incidence of energy vulnerability, the literature has been careful to highlight that there are in fact a multitude of factors at play, with complex and dynamic interactions (Bouzarovski, 2014; Middlemiss and Gillard, 2015). These include additional demographic factors (such as households size and composition, and health conditions), as well as social and economic structural factors. Energy vulnerability is socially situated - depending to some degree on cultural expectations around acceptable standards of living, social customs and activities, and quality of energy services (Bouzarovski, 2014). As such, it is important to understand broader trends in relation to both income and wealth inequality in considering specific energy vulnerability.

Multiple analyses show that both income and wealth inequality have been rising in Australia since the mid-1990s (see for example OECD, 2015; Fletcher and Guttman, 2013; Wilkins, 2015; and Dollman et al, 2015). The growing divide in income and wealth distribution appears to be most pronounced at either end of the income spectrum. For example, in 2009/10 the top 20 per cent of households earned $42 \%$ of total household income, whereas the bottom 20 per cent of households earned only 7\% of income (Dollman et al, 2015). Wealth concentration is observed to be even more marked than income inequality. For example, in 2013/14 the share of total net wealth held by the top 20 per cent of households was found to be $62 \%$ (Dollman, 2015). However, trends in these variables are not universally accepted. Fenna and Tapper (2015) suggest that the growth in inequality has been largely overstated, with wealth and income inequality generally stable since 2000. The most recent findings of Biddle and Montaigne (2017, p. 17) show that all Australian capital cities have experienced an increase in total inequality with disproportionate increases in Brisbane, Perth and Darwin. Importantly, within suburb inequality increased in every capital city.

\footnotetext{
${ }^{2}$ For the purposes of this article, energy-related financial hardship is defined as an inability to pay for electricity or gas, despite a willingness to do so. 


\subsection{Important trends in relation to income equality}

Despite the acknowledged limitations, income proxies are for practical purposes widely used as a measure of disadvantage. ACOSS (2016, p. 9) describes poverty as being unable to afford 'socially perceived necessities - things that a majority in the community agrees that no-one should have to go without' - but employs a recognised 'poverty line' to indicate its presence. The 'poverty line' is an income measure relative to 50 percent of median household income (adjusted using an equivalence scale). Using this measure, ACOSS (2016) found that about $13 \%$ of the Australian population - or close to 3 million people - were living below the poverty line in 2014 . This has not materially changed over the last decade (ACOSS, 2016). The highest incidence of poverty is reported to be experienced by lone parents (33\%) and unemployed households (63\%). Around $60 \%$ of those living below the poverty line are renters and less than $16 \%$ are homeowners, with this split relatively evenly between mortgage holders and outright owners (ACOSS, 2016). 
Figure 1: Average weekly earnings and inflation measures

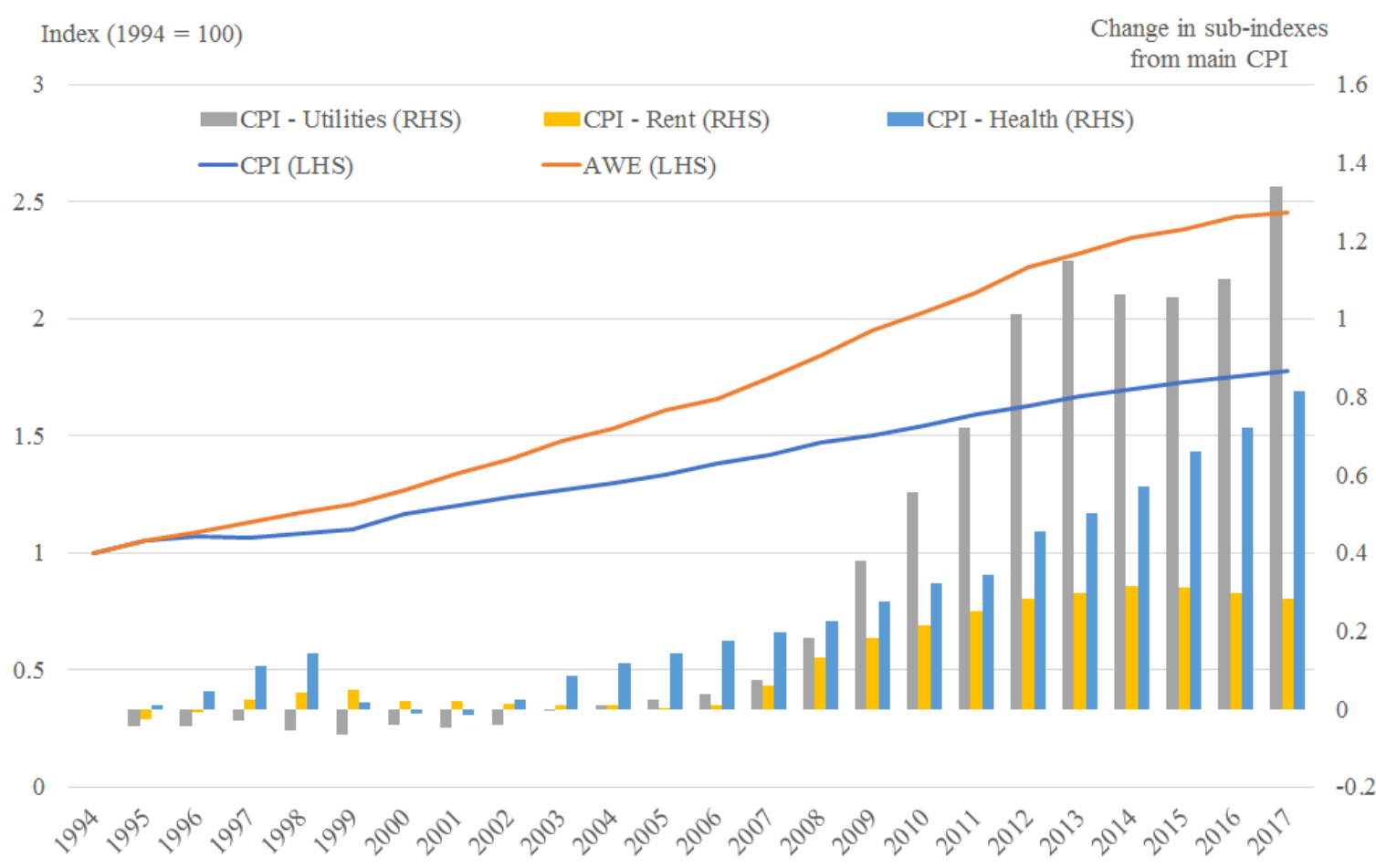

Source: Adapted from the Australian Bureau of Statistics (ABS)

For the purposes of this article, we have considered unemployment benefits (known as Newstart in Australia) and Average Weekly Earnings (AWE) as proxies for assessing trends in relation to income. Age pensions are indexed to average earnings (AWE) whereas Newstart is indexed to general inflation (measured through the Consumer Price Index - CPI). Figure 1 demonstrates that there has been a material difference in the income growth of wages, unemployment benefits and age pensions. Average weekly earnings (and thereby age pensions), have grown by a much greater rate than general inflation (and thereby unemployment benefits). This has led to a divergence in the adequacy of unemployment benefits as compared with age pensions 
To demonstrate the inequity of the rate of growth of these income sources, we have analysed an important subset of inflation: utilities; rent; and health. Figure 1 shows the growth in pricing of these important essential household needs over and above general inflation is material. This has had a disproportionate impact on households whose income sources are tied only to general inflation and not average weekly earnings. It is therefore unsurprising that a majority of those living below the poverty line receive social security payments with only a third relying on wages as their main source of income. There is therefore a greater incidence of poverty for unemployed people below the age of 65 than those above this age (ACOSS, 2016).

Saunders and Bedford's (2017) approach for assessing income adequacy for low-paid and unemployed families is not dissimilar to the landmark Harvester 'living wage' judgement in $1907^{3}$ but more relevant to the workforce and societal structure of today. In their analysis, they apply a 'budget standard' which indicates how much income a household needs to achieve a particular standard of living. The budget is built from the bottom up - itemising and costing every required item of expenditure - and will vary according to household composition. It necessarily requires judgements about both the appropriate standard of living and what is needed to achieve that standard, and is supported by behavioural and experiential data to ground the budget in a realistic and current social context.

\footnotetext{
${ }^{3}$ The Harvester Australian legal judgement was based on the concept that a minimum wage should be based on the cost of living for a worker and their family. It was a key building block of Australia's industrial relations system.
} 
In applying this approach to the current Australian context, Saunders and Bedford (2017) settled on the Minimum Income for Healthy Living (MIHL) standard developed and applied within the UK public health literature. The standard is designed to ensure that all individuals are able to lead healthy lives and participate in society. They argue that standards used to assess the adequacy of social security payments have not been revised for two decades and therefore do not reflect current social practices or community norms. Their analysis finds that single adults and sole parents in full-time work being paid the minimum wage have disposable incomes that exceed the MIHL, but the incomes of all other low paid families fall below it. For unemployed families receiving social security payments the shortfall varies between $\$ 47$ and $\$ 126$ a week (Saunders and Bedford, 2017).

Rental costs have grown at much higher rates than general inflation (a point established by the analysis in Figure 1). To accurately account for housing costs, Saunders and Bedford (2017) built on their preliminary findings by utilising a 'Rental Threshold' approach to gross up the MIHL budget. Low income households were assumed to occupy a 'middle suburb' and unemployed households an 'outer suburb' of a capital city. Dwelling sizes were selected to be broadly representative of the requirements for each family type. Their results are presented in Table 1. 
Table 1: Weekly budget standards, income and household budget deficits

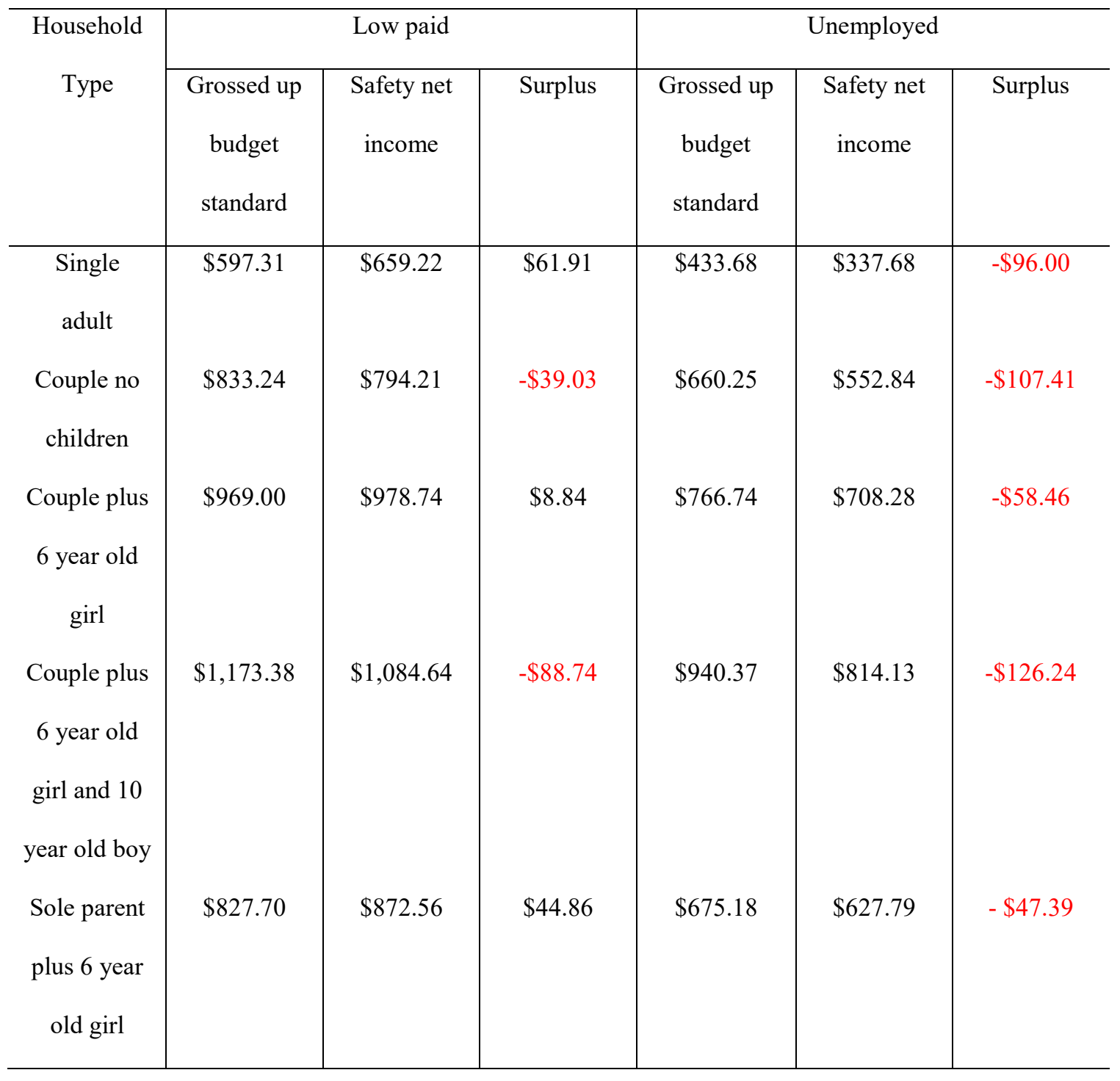

Source: Saunders and Bedford (2017)

Table 1 shows that Saunders and Bedford (2017) found that only three of the ten household cohorts presented would have an income surplus. In all five households receiving unemployment 
benefits there is a deficit in the income required to achieve an adequate standard of living. We contend that this may be resulting in the rationing of essential services such as energy, food and education, or an in inability to pay for these services. Their analysis suggests that the primary cause of the current inadequacy of the unemployment allowance is its automatic indexation to CPI alone, without reflecting any changes in average wages over the same period which modify community expectations around acceptable standards of living. This can be contrasted with the minimum wage which is reviewed annually by an independent umpire (now the Fair Work Commission) and has been rising steadily since 1998, although more slowly than average disposable income (Saunders and Bedford, 2017). In fact, concerns about the ongoing adequacy of Australia's unemployment benefits are not new and were reflected in the Henry Review ${ }^{4}$ and in the submissions of a wide range of stakeholders to a 2012 Senate Committee Inquiry into the issue (Klapdor, 2014).

\footnotetext{
${ }^{4}$ The Henry Review was a review of Australia's taxation system in 2010 by Commonwealth Treasury Secretary Ken Henry. It found, 'a continuous decline in Newstart Allowance against community standards would have major implications for payment adequacy and the coherence - in terms of horizontal equity - of the income support system.' - see https://taxreview.treasury.gov.au/content/FinalReport.aspx?doc=html/publications/Papers/Final_Report_Part_2/chapter_fl-2.htm, Accessed online 1 February 2018.
} 


\subsection{The importance of housing in relation to energy-related financial hardship}

It is beyond the scope of this article to fully address the broader issue of housing affordability in the Australian context. Housing affordability is generally thought to be 'stressed' when housing costs exceed around $35 \%$ of disposable income. There are numerous studies that seek to understand housing affordability in both a broader and Australian context (see Stone, 2006; Tanton and Phillips, 2013; and Rowley, Ong \& Haffner, 2015). Rather than deepening the understanding of housing affordability in Australia, this article is concerned with how trends in home ownership and occupancy tenure intersect with changes in energy technology to impact on energy affordability.

Home ownership is a critical determinant of a household's ability to participate in markets for energy efficiency and distributed energy solutions such as solar PV (Orton et al, 2017). Home owners do not face the same barriers as renters when investing capital to improve energy efficiency or install embedded generation and storage. Housing quality also has quite significant impacts on household energy consumption. Cheaper housing has tended to be of poorer quality with low energy efficiency ratings (Chester, 2014; Chester, 2015; Hernandez and Bird, 2012). To the extent they are homeowners, low income households may have limited access to capital to improve a dwellings thermal performance, and also be limited in their ability to upgrade appliance stocks to more efficient models (Chester, 2014). Tenants face additional barriers to improving the efficiency of dwellings. Landlord consent is usually required and is seldom provided even for small scale upgrades (QCOSS, 2017). Relatively short contract tenure also impacts upon incentives to make more capital-intensive improvements to rented property, such as the replacement of hot water systems or installation of solar PV (QCOSS, 2017). Indeed literature on 'fuel poverty' or 'energy vulnerability' attributes this state largely to the confluence of three key factors: low income, rising energy prices and housing conditions (Chester and Morris, 2012; Chester, 2014; Bouzarovski, 2014; Chester, 2015). 
There have been declining rates of homeownership among specific cohorts of the general population. Australia's median real house price has almost quadrupled since 1970, while real wages have grown at half this pace (CEDA:Yates, 2017). Perhaps not surprisingly then, homeownership peaked in Australia in the late 1960 s at a rate of almost $73 \%$ and has since declined to a current rate of about $67 \%$ (CEDA:Stapledon, 2017). There has been a corresponding increase in the number of homeowner households with mortgage indebtedness (rising from $61 \%$ in 1984 to $70 \%$ in $2015-16$ (ABS, 2016)), as well as to the ratio of that indebtedness to household income (CEDA:Ong, 2017; Wood and Ong 2017).

These headline homeownership figures mask the distributional changes in homeownership amongst the Australian population. The rate of homeownership of Australians aged 55 and over has remained fairly constant at $80-84 \%$ between the late 1960 s and today (CEDA:Stapledon, 2017). However, rates of homeownership of Australians aged between 25-34 have fallen from a peak of $60 \%$ to a current rate about $45 \%$, and for Australians aged between 34-44 homeownership has fallen from a peak of $75 \%$ to a current rate of $62 \%$ (CEDA:Stapledon, 2017). In addition to the intergenerational equity issues apparent from these figures, there are likely to be more subtle intra-generational issues where younger Australian homeowners are disproportionately represented by those whose parents' wealth allowed them to assist their children into the market (CEDA:Yates, 2017). 
Average housing costs have increased more substantially for renters than for any other cohort. Over the last decade real average housing costs have risen by $62 \%$ for private renters, $42 \%$ for owners with a mortgage and $45 \%$ for public renters (ABS 2014). As with many essential items, low-income households spend a greater proportion of their income on housing than the average Australian household. This is despite their absolute housing costs tending to be lower. QCOSS (2016) identified housing costs as the single biggest financial burden, especially for those who rent in the private market. Wood and Ong (2017) found that the incidence of housing stress for low-income renters increased from 41 per cent to 69 per cent over a 30-year period to 2013.

Not only do changes in home asset values, homeownership rates and relative housing costs have implications for the accrual of wealth among different demographic groups, a deterioration in housing affordability is observed to have a range of flow-on impacts. Affordable housing has tended to be located further from urban centres reducing access to employment opportunities and other amenities and increasing travel time and costs (CEDA, 2017). This can entrench social disadvantage among vulnerable groups, limiting opportunities to improve their economic position.

\subsection{The importance of understanding heterogeneous energy consumption}


Low-income households spend a greater proportion of weekly income on energy costs

(Simshauser et al, 2011). This is exacerbated by the impact that housing conditions have on household energy consumption, as well as by household composition and circumstances which may influence capacity to change energy demand (Chester, 2014; and Chester, 2015). Domestic fuel and power costs account for approximately $3 \%$ of average Australian weekly expenditure, a figure that has remained relatively stable since the first HES survey in 1984 (ABS, 2017). However, this rises to $4.4 \%$ for those in the lowest income quintile and is only $2 \%$ for those in the highest income quintile. Given that housing conditions operate as a substantial constraint on the ability of some low-income households to reduce energy demand, they are likely to be particularly exposed to changes in energy prices (Chester, 2014).

But the use of averages in relation to energy consumption can be misleading for policy makers. Simshauser and Nelson (2014) considered the nature of electricity consumption and income and demonstrated the significant heterogeneity in relation to consumption patterns. Their study identified the 'family formation' demographic as being the most vulnerable to financial hardship given above average consumption, driven by more persons in the home, and low income per person. The heterogeneity identified in the study is replicated in Table 2.

Table 2: Percentage of consumers by income and consumption band

\begin{tabular}{c|c|c|c|c|c}
\hline Income & $<4 \mathrm{MWh}$ & $4-6 \mathrm{MWh}$ & $6-8 \mathrm{MWh}$ & $8-12 \mathrm{MWh}$ & $>12 \mathrm{MWh}$ \\
\hline$<\$ 30,999 \mathrm{pa}$ & 5 & 5 & 4 & 3 & 1 \\
$\$ 31,000-\$ 70,999$ & 5 & 8 & 9 & 8 & 2 \\
$\$ 71,000-\$ 150,999$ & 4 & 6 & 8 & 10 & 2 \\
$>\$ 151,000$ & 0 & 0 & 1 & 1 & 1 \\
N/A & 2 & 3 & 3 & 26 & 11 \\
Total (sum = 100) & 16 & 22 & 25 & 26 & 4 \\
\hline
\end{tabular}


Table 2 demonstrates the heterogeneous nature of household electricity consumption and income. While it is true that in broad terms there is a trend towards high electricity consumption in higher income households, there are outliers that require consideration. Around four percent of homes use significantly more electricity than average and have a very low household income. Such households would no doubt be at severe risk of energy-related financial hardship as they could be spending more than $10 \%$ of their income on electricity, a benchmark used to define 'energy poverty' (see Simshauser et al, 2011). Our analysis in the subsequent section confirms this.

A more recent survey of households by the Independent Pricing and Regulatory Tribunal of New South Wales (IPART) has reinforced the findings of Simshauser and Nelson (2014). IPART (2015) found that the implied average spend on electricity as a proportion of household income halved for the highest income houses when compared with those on low incomes.

The IPART data shows that lower-income households are much more likely (at a rate of around $18 \%$ ) to experience financial difficulty paying their energy bills than high-income households (at a rate of around 5\%). Low-income households with a greater propensity to experience financial difficulty are those with more children, without solar PV and which are renting their home or paying off a mortgage (Frontier Economics, 2016). For example, 25\% of one or two person lowincome households paying rent experienced financial difficulty as compared with $42 \%$ of three or more person low-income households paying rent (IPART, 2015). And only $8 \%$ of one or two person low-income households that owned their home outright experienced financial difficulty (IPART, 2015).

2.4 The intersection of income, housing and heterogeneous consumption 
A number of studies have examined the coping strategies of the disadvantaged experiencing 'fuel poverty' or 'energy vulnerability' (for example Brunner et al, 2012; Heflin et al, 2011; Chester, 2014; Chester, 2015; Middlemiss and Gillard, 2015; and NCOSS, 2017). These strategies can involve forgoing lighting, heating or cooling certain rooms, or going without clothing, food, medical treatment or other essentials. Flow-on impacts from these material hardships have been recorded to include physical discomfort, reduced mental well-being, loneliness and social isolation, strains within household relationships and concerns around the well-being of dependent children (Chester, 2014; Bouzarovski, 2014; and NCOSS, 2017).

These studies also find that coping strategies are ultimately limited and that more sustainable improvements in living standards and energy affordability can only be achieved by addressing root causes in terms of housing conditions, income and energy costs. Chester $(2014,2015)$ notes that, historically, policy treatments have been heavily weighted to income support and energy cost relief (such as rebates and concessions), while programs targeted at improving energy efficiency for vulnerable households have been far more limited and often targeted at low-cost, low-impact improvements like light-bulb replacements or encouraging behavioural energy efficiency measures.

Whether low-income will translate into broader disadvantage will be influenced by 'personal capabilities and family circumstances; the support they receive; the community where they live (and the opportunities it offers); life events; and the broader economic and social environment' (McLachlan et al, 2013, p. 2). The same holds true for energy vulnerability. Income, housing and consumption will no doubt be key variables in indicating whether a household is at risk of experiencing energy-related financial hardship. As Bouzarovski (2014) notes, not all low-income households will suffer from 'energy vulnerability'. For example, low-income Australian households who own their home outright are less likely to suffer energy vulnerability due both to 
lower ongoing housing costs, and the greater ability to pursue more significant energy efficiency measures, such as insulation, solar hot water and solar PV (NCOSS, 2017). 


\section{Method of analysis}

We have analysed data from around 31,000 Australian electricity customers to better understand the incidence and potential drivers of energy-related financial hardship such as age, household composition and structure. The data was obtained from AGL Energy Ltd, one of Australia's largest electricity and gas retailers and represents key statistics related to the AGL hardship program, Staying Connected, as at June $2017^{5}$. The program is open to any customer experiencing a period of financial hardship, where the customer has a willingness to pay but not the capacity to pay. Customers on hardship programs are offered support in the form of tailored payment plans which take into account a customer's capacity to pay, energy efficiency advice, information on government-funded energy concessions and emergency relief grants and referral to other support services such as independent financial counsellors. Customers that participate are protected from disconnection on the condition they are meeting agreed payment plan commitments or otherwise maintain their engagement with AGL.

We have also applied an estimate of the energy spend for the same cohorts presented in Saunders and Bedford (2017) utilising both relatively high priced 'standing offer' tariffs and comparatively low 'discounted market offer' tariffs. The purpose of this analysis is to consider how vulnerable and hardship households may be impacted by complexities in navigating the competitive retail market or certain commercial strategies such as restrictions on product availability offered to customers on the basis of their credit history. Our analysis also allows us to make observations in relation to optimal design of concessions frameworks. In particular, by identifying the heterogeneous nature of consumption, we are able to make observations about the need for concessions to be variable and correlated with consumption.

\section{Results of analysis}


An overview of the dataset being analysed is presented in Table 3 . There are notable jurisdictional differences in the incidence of customer hardship in Australia's NEM jurisdictions. Approximately 1\% of customers in New South Wales and Queensland are participating in the hardship program. This is much higher in the other states with $1.6 \%$ participating in Victoria and 2.1\% participating in South Australia. The average outstanding debt is highest in South Australia at $\$ 3,070$. This is around $50 \%$ higher than in Queensland which has the lowest average debt at $\$ 2,147 .{ }^{6}$ Such relative outcomes are not surprising given income and energy pricing trends across the four states. ${ }^{7}$

\footnotetext{
${ }^{6}$ Note these figures relate to per customer debt, where around half purchase only gas OR electricity from AGL and the other half purchase both gas AND electricity form AGL.

${ }^{7}$ In broad terms, South Australia and Victoria have relatively lower incomes and higher prices. For relative incomes, see http://www.abs.gov.au/AUSSTATS/abs@.nsf/Lookup/6523.0Main+Features22011-12 (Accessed online on 15 January 2018) and prices see https://www.aer.gov.au/system/files/AER $\% 20$ State $\% 20$ of $\% 20$ the $\% 20$ energy $\% 20$ market $\% 202017 \% 20-\% 20$ A4.pdf (Accessed $19^{\text {th }}$ December 2017). 
Table 3: Hardship customer dataset description

\begin{tabular}{c|c|c|c|c|c}
\hline State & Customers & $\begin{array}{c}\text { No. Energy } \\
\text { Contracts }\end{array}$ & Debt & Average Debt & $\begin{array}{c}\text { Hardship } \\
\text { penetration }\end{array}$ \\
\hline NSW & 9,376 & 12,988 & $\$ 21.7 \mathrm{M}$ & $\$ 2,310$ & $1.03 \%$ \\
QLD & 4,207 & 4,715 & $\$ 9.0 \mathrm{M}$ & $\$ 2,147$ & $1.11 \%$ \\
SA & 7,238 & 9,958 & $\$ 22.2 \mathrm{M}$ & $\$ 3,070$ & $2.11 \%$ \\
VIC & 10,283 & 17,921 & $\$ 26.3 \mathrm{M}$ & $\$ 2,559$ & $1.58 \%$ \\
Total & 31,104 & 45,582 & $\$ 76,686$ & $\$ 2,522$ & $1.36 \%$ \\
\hline
\end{tabular}

Source: AGL customer database

Across AGL's residential customer base, approximately $25 \%$ of customers are eligible for an energy concessions rebate. ${ }^{9}$ However, just over $55 \%$ of customers participating in AGL's hardship program are eligible. There is therefore a material overrepresentation of concession customers in the hardship program, indicating that low-income households reliant upon government income support are indeed more vulnerable to energy bill stress. But only $3 \%$ of AGL customers who are eligible for an energy rebate are participating in the hardship program. This supports the thematic in the existing literature that not all low-income households will be vulnerable to energy bill stress and other factors may also be relevant. Around $45 \%$ of customers participating on the hardship program do not receive an energy rebate, further underlining that income is not the sole determinant of energy vulnerability.

$\underline{\text { Table 4: Hardship program debt, duration and consumption levels }}$

\footnotetext{
${ }^{8}$ Penetration is defined as the number of hardship customers divided by total customer accounts.

${ }^{9}$ Governments tend to apply energy rebates to customers using income as a proxy for vulnerability and therefore eligibility. Most commonly this is achieved by specifying the holding of certain means-tested Commonwealth issued concession cards (such as a Centrelink pensioner concession card or Centrelink health card) as a qualifying criterion for State-provided energy rebates.
} 


\begin{tabular}{c|c|c|c|c|c}
\hline & Debt per & Program & Annual elec & Annual gas & $\%$ of ongoing \\
& customer & duration & consump & consump (MJ) & consump met by \\
Count & 31,094 & 31,397 & - & - & - \\
Mean & $\$ 2,548$ & 17 & 8,307 & 54,525 & $94 \%$ \\
Median & $\$ 1,737$ & 14 & 7,300 & 40,880 & $85 \%$
\end{tabular}

Source: AGL customer database

Table 4 provides a summary of some key statistical observations in relation to the hardship dataset. A number of conclusions can be drawn from this data set. Firstly, there is a large spread of customers with unique characteristics. The median average debt per customer is significantly lower than the mean. This spread is reflected in the average annual consumption of both electricity and gas. Mean consumption is between 10 and $15 \%$ higher than median consumption. Importantly, the average payment plan is not sufficient to meet ongoing billed consumption. There is clearly an issue related to income adequacy for some of these customers given the relatively high proportion of customers unable to make payments that cover their energy usage. Our analysis of the hardship data therefore supports the general thematic identified in Section 2.

Furthermore, customers participating in the hardship program use significantly more energy than the general population. Figure 2 shows the average yearly electricity consumption for NEM household customers and those participating on the hardship program, as well as for concession customers as a subset of those participating in the hardship program. New South Wales customers participating in the hardship program use 58\% more electricity on average. In Queensland, South Australia and Victoria, hardship customers use $62 \%, 59 \%$ and $41 \%$ more energy than the broader population average respectively. Concession customers as a subset of customers participating in the hardship program use slightly less than the hardship average but still significantly more than 
the general population average $(53 \%, 52 \%, 49 \%$ and $37 \%$ more in New South Wales, Queensland, South Australia and Victoria respectively).

Similar trends are observed when looking at gas consumption for these customer segments. Figure 3 shows that New South Wales, Queensland, South Australian and Victorian customers participating in the hardship program use $50 \%, 29 \%, 26 \%$ and $30 \%$ more gas than the average customer respectively. Concession customers as a subset of customers participating in the hardship program use less than the broader hardship cohort but still significantly more than the general population average. There are no concession rebates for gas in South Australia.

Despite payment plans for hardship customers being based on an assessment of a number of factors, including capacity to pay, only $14 \%$ of hardship customers are on payment plans that meet both the ongoing costs of their consumption, as well as contributing to paying off accrued debt. About $20 \%$ of hardship customers are on payment plans that cover their ongoing consumption costs but no amount of accrued debt. Some $60 \%$ are on payment plans that neither cover the ongoing costs of their consumption, nor their accrued debt. Customers with a concession are slightly more likely to be on a plan that does not cover costs $(63 \%)$. Hardship customers are therefore unlikely to improve their energy-related financial hardship unless they are able to reduce their consumption or increase their repayments through higher disposable income. Both options are unlikely given the inflexible nature of income capacity and the limited ability to access technologies that may reduce consumption.

Figure 2: Average household electricity consumption by state 
Consumption $(\mathrm{kWh})$

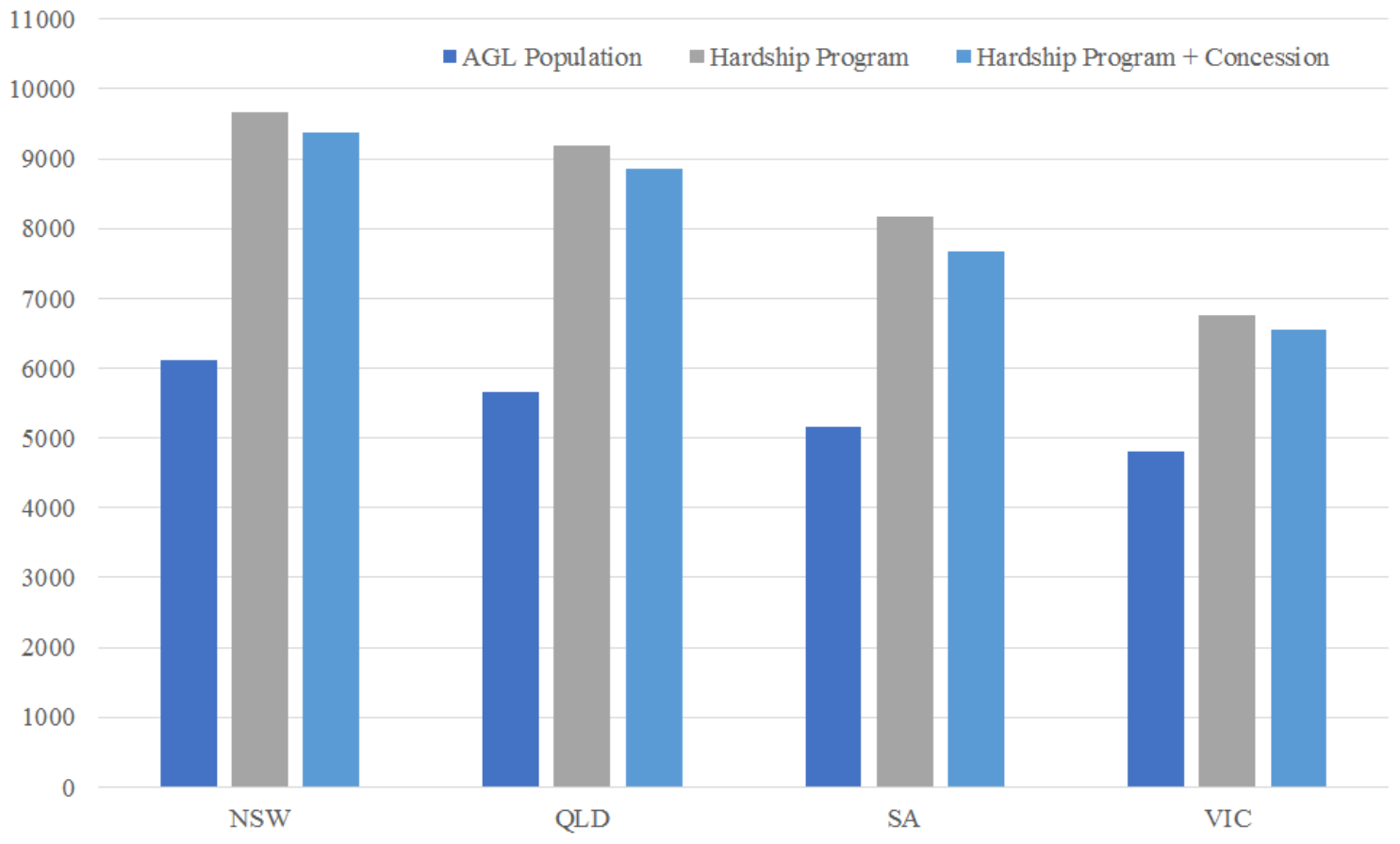

Source: Analysed from AGL dataset 
Figure 3: Average household gas consumption by state

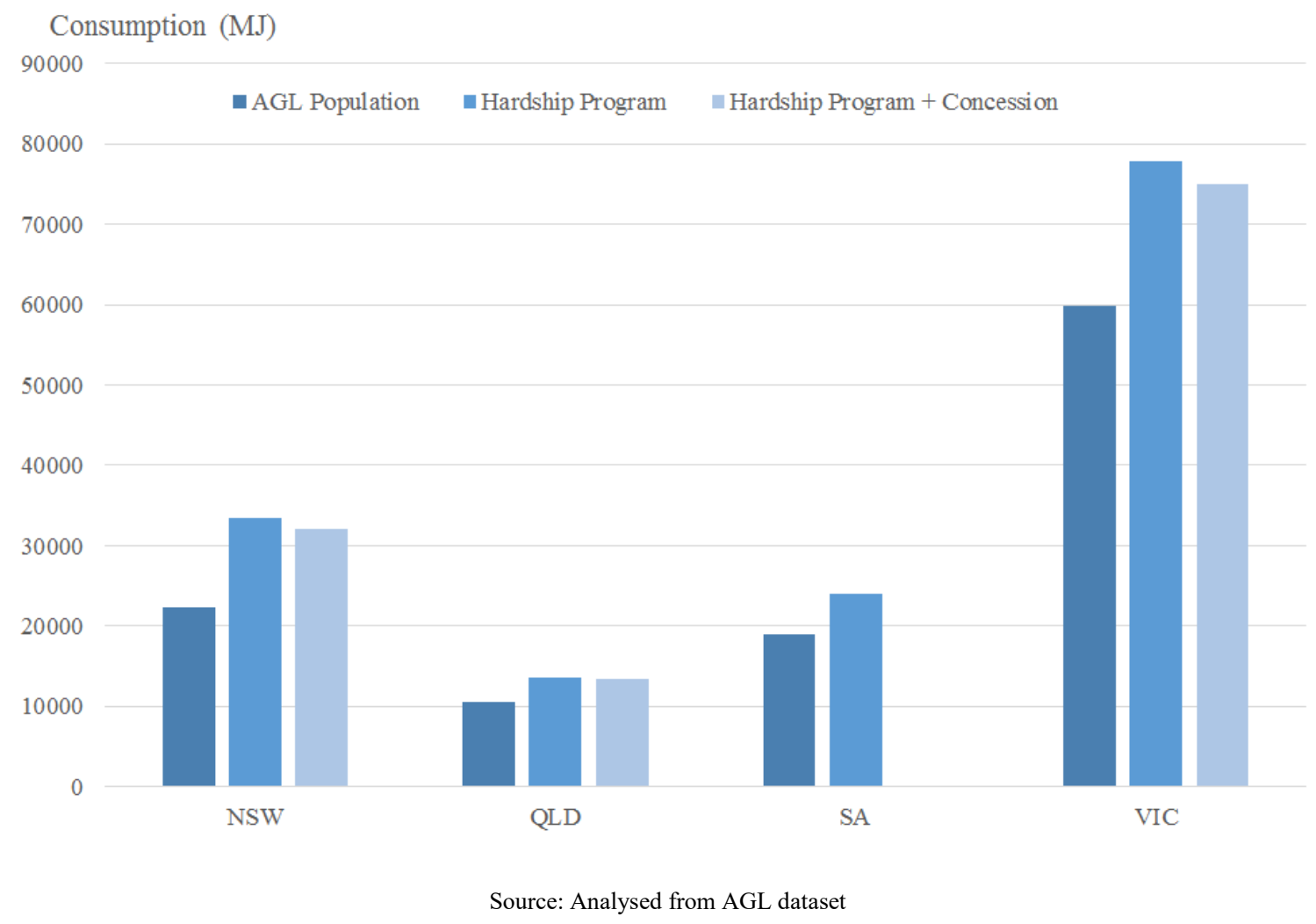

Table 5: Key demographic data of hardship customer households

\begin{tabular}{c|c|c}
\hline & No. of Bedrooms & $\begin{array}{c}\text { Average age of account } \\
\text { holder }\end{array}$ \\
\hline Count & 28,062 & 31,094 \\
Mean & 3 & 46 \\
Median & 3 & 45
\end{tabular}

Source: Adapted from AGL customer dataset

Table 5 provides two key demographic variables collected by AGL in managing the hardship program. Over $76 \%$ of hardship households have three or more bedrooms. Around $70 \%$ are in 
houses with the remainder in apartments or other dwelling types. Importantly, $54 \%$ of properties are over 30 years old. Only $6 \%$ of hardship customers have embedded solar PV installed at their premises. This is less than half the broader population where $13 \%$ of customers have installed PV. The spread of households by bedroom count is presented in Figure 4.

Figure 4: Spread of hardship households by bedroom count

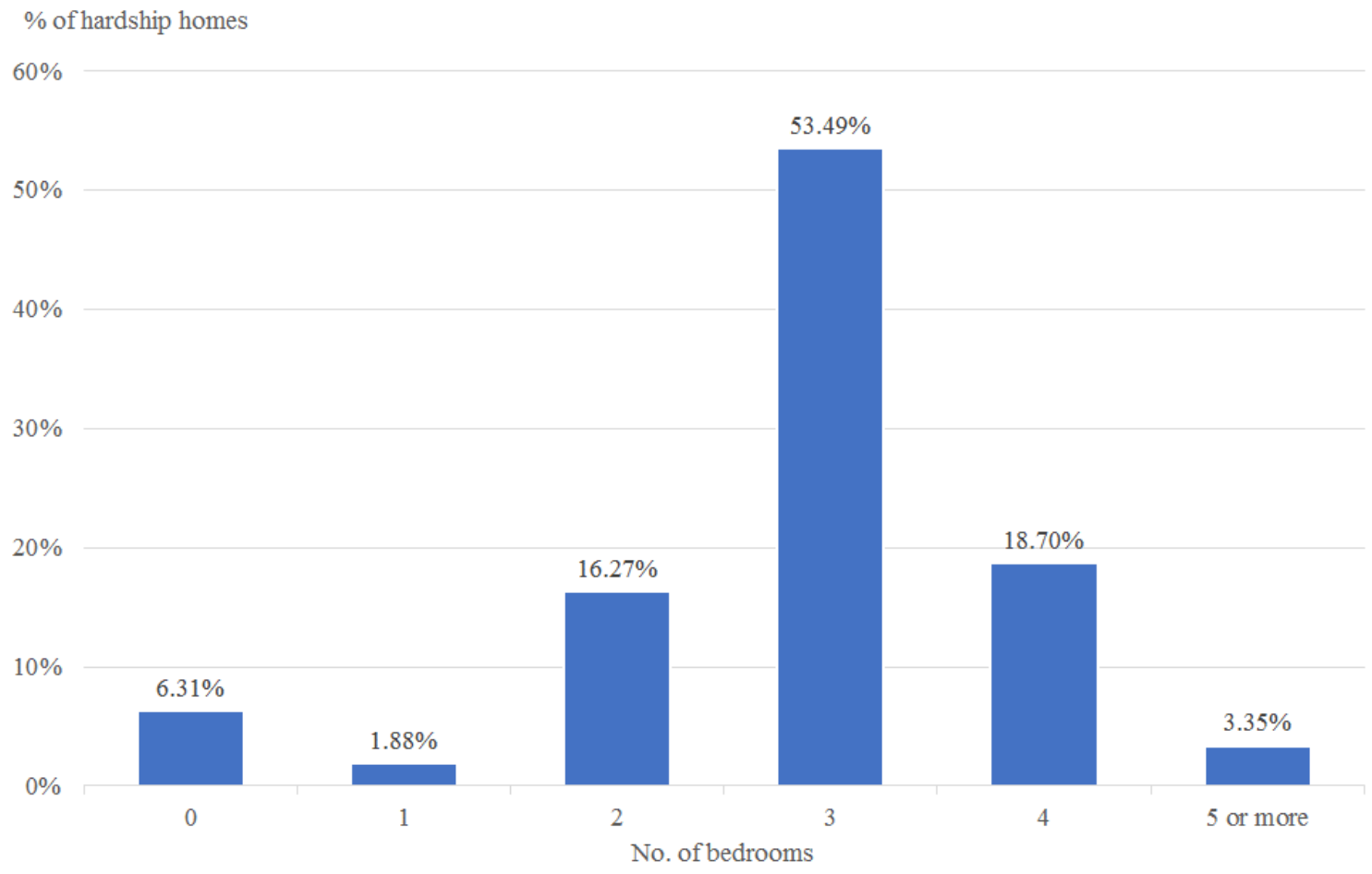

Source: Adapted from AGL customer dataset 


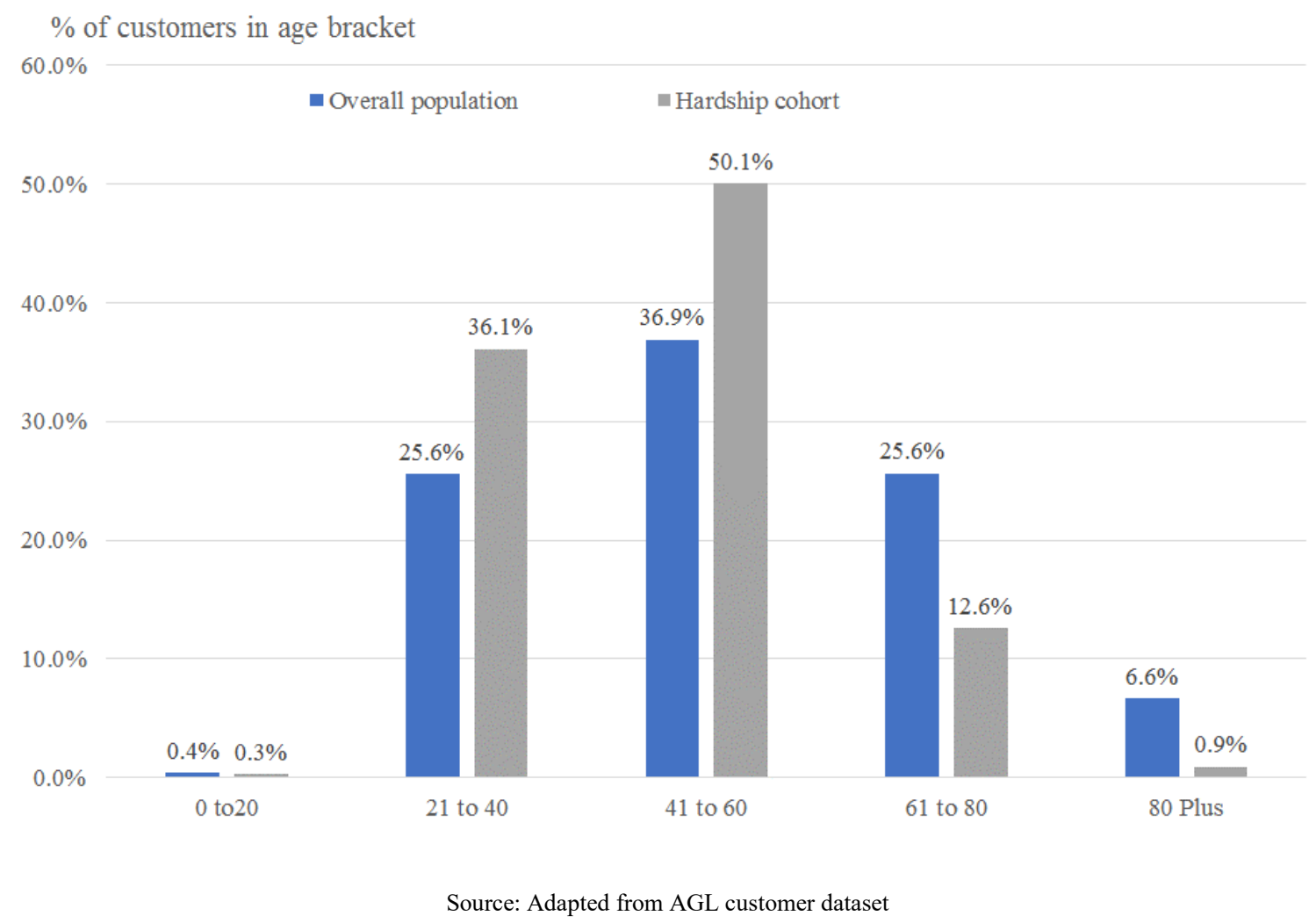

Consistent with the analysis of Simshauser and Nelson (2014), there is a higher than average proportion of family formation cohort households in hardship. The distribution of customers by age is shown in Figure 5. There is a far greater representation of customers aged 21-40 (50\%) and 41-60 (37\%) than the general customer population (37\% and 25\% respectively). This means that there is a significant underrepresentation of account holders aged 60 and older, with $32 \%$ of retail account holders falling within this bracket but only $13 \%$ of those participating on the AGL hardship program. These findings are consistent both with the distribution of home-ownership across the Australian population and its relationship to energy vulnerability, as well as the literature indicating that the age pension is better able to support an adequate standard of living than social security safety-nets for other demographics under 65 years of age.

To understand the proportion of energy spend relative to income, we have applied an estimate of the energy spend for the same cohorts presented in Saunders and Bedford (2017). We utilised 
relatively high priced 'standing offer' tariffs and comparatively low 'discounted market offer' tariffs sourced from Nelson et al (2018) for the Victorian market. ${ }^{10}$ We have analysed these different tariffs to demonstrate the importance of vulnerable customers having access to the lowest possible tariffs. Several Australian electricity retailers currently utilise credit screening metrics which may result in a vulnerable household only being offered the highest standing offer tariffs. The purpose of our analysis is to demonstrate that this practice may be entrenching hardship. Consumption estimates for our analysis are not observable but are instead sourced from linear deviations from the mean consumption of customers on the hardship program based upon the number of people in the home. The results are presented in Table 6 and Table 7.

Table 6: Proportion of weekly safety net income on energy (low paid households)

\begin{tabular}{|c|c|c|c|c|c|}
\hline $\begin{array}{c}\text { Household } \\
\text { Type }\end{array}$ & $\begin{array}{c}\text { Safety Net } \\
\text { Income }\end{array}$ & $\begin{array}{c}\text { Estimated } \\
\text { Energy Spend } \\
\text { (Standing } \\
\text { Offer Tariff) }\end{array}$ & $\%$ of Income & $\begin{array}{c}\text { Estimated } \\
\text { Energy Spend } \\
\text { (Market } \\
\text { Discount Offer } \\
\text { Tariff) }\end{array}$ & $\%$ of Income \\
\hline $\begin{array}{l}\text { Single } \\
\text { adult }\end{array}$ & $\$ 659.22$ & $\$ 17.09$ & 2.59 & $\$ 13.26$ & 2.01 \\
\hline $\begin{array}{l}\text { Couple no } \\
\text { children }\end{array}$ & $\$ 794.21$ & $\$ 34.19$ & 4.30 & $\$ 26.52$ & 3.34 \\
\hline $\begin{array}{l}\text { Couple plus } 6 \\
\text { year old girl }\end{array}$ & $\$ 978.74$ & $\$ 51.28$ & 5.24 & $\$ 39.78$ & 4.06 \\
\hline $\begin{array}{l}\text { Couple plus } 6 \\
\text { year old girl } \\
\text { and } 10 \text { year } \\
\text { old boy }\end{array}$ & $\$ 1,084.64$ & $\$ 68.37$ & 6.30 & $\$ 53.03$ & 4.89 \\
\hline
\end{tabular}

\footnotetext{
${ }^{10}$ Nelson et al (2018) developed standing offer and market discount tariff estimates to provide a reasonable approximation of the
} upper and lower boundaries of potential retail pricing offers in a competitive market. 


\begin{tabular}{c|c|c|c|c|c} 
Sole parent & $\$ 872.56$ & $\$ 51.28$ & 5.88 & $\$ 39.78$ & 4.59 \\
plus 6 year old & & & & & \\
girl & & & & & \\
\hline
\end{tabular}

Source: Analysis derived from AGL customer dataset and Saunders and Bedford (2017)

Table 7: Proportion of weekly safety net income on energy (unemployed)

\begin{tabular}{|c|c|c|c|c|c|}
\hline $\begin{array}{c}\text { Household } \\
\text { Type }\end{array}$ & $\begin{array}{c}\text { Safety Net } \\
\text { Income }\end{array}$ & $\begin{array}{c}\text { Estimated } \\
\text { Energy Spend } \\
\text { (Standing } \\
\text { Offer Tariff) }\end{array}$ & $\%$ of Income & $\begin{array}{c}\text { Estimated } \\
\text { Energy Spend } \\
\text { (Market } \\
\text { Discount Offer } \\
\text { Tariff) }\end{array}$ & $\%$ of Income \\
\hline $\begin{array}{l}\text { Single } \\
\text { adult }\end{array}$ & $\$ 337.68$ & $\$ 17.09$ & 5.06 & $\$ 13.26$ & 3.93 \\
\hline $\begin{array}{l}\text { Couple no } \\
\text { children }\end{array}$ & $\$ 552.84$ & $\$ 34.19$ & 6.18 & $\$ 26.52$ & 4.8 \\
\hline $\begin{array}{l}\text { Couple plus } 6 \\
\text { year old girl }\end{array}$ & $\$ 708.28$ & $\$ 51.28$ & 7.24 & $\$ 39.78$ & 5.62 \\
\hline $\begin{array}{l}\text { Couple plus } 6 \\
\text { year old girl } \\
\text { and } 10 \text { year } \\
\text { old boy }\end{array}$ & $\$ 814.13$ & $\$ 68.37$ & 8.4 & $\$ 53.03$ & 6.51 \\
\hline $\begin{array}{c}\text { Sole parent } \\
\text { plus } 6 \text { year old } \\
\text { girl }\end{array}$ & $\$ 627.79$ & $\$ 51.28$ & 8.17 & $\$ 39.78$ & 6.34 \\
\hline
\end{tabular}

Source: Analysis derived from AGL customer dataset and Saunders and Bedford (2017) 
The results of our analysis in Tables 6 and 7 are instructive. There are three conclusions that can be drawn. The proportion of income spent by a household on energy increases as the number of people in the home increase. This aligns with the findings of Simshauser and Nelson (2014) that higher numbers of people in a household (established by measuring the number of bedrooms) is related to lower income per person in the household and higher than average energy consumption. The second conclusion is that unemployed households have an energy spend to income ratio more than $30 \%$ higher than low-paid households. And thirdly, it is apparent that households that 'shop around' can significantly reduce the proportion of their income spent on energy (given the delta between estimated energy spend under standing offer tariffs and market discount offer tariffs). This finding is consistent with recent studies on price dispersion in the Australian market (see Simshauser and Whish-Wilson, 2017).

\section{Policy recommendations and discussion}

The analysis in the preceding section shows that there is a conundrum relating to income, energy efficiency and consumption. Hardship households tend to consume more energy than an average household. Ideally, these households would deploy energy efficiency measures which would reduce their energy spend and increase their remaining disposable income. However, they lack the upfront capital resources required to be able to deploy energy efficiency measures and new technologies (e.g. solar PV). A number of policy recommendations follow from these findings. We have grouped these into four categories: improving consumer outcomes in the energy market; income adequacy; consumption measures; and improvements to housing tenure. 


\subsection{Improving consumer outcomes in the energy market}

There is strong existing focus on measures to improve the effectiveness of the retail market. The Australian Government has commissioned reviews of the market by the Australian Competition and Consumer Commission (ACCC, 2017) and electricity retailers have made a series of commitments to improve transparency and comparability. ${ }^{11}$ Our analysis aligns with that of Simshauser and Whish-Wilson (2017) and Nelson et al (2018) that shows there are significant benefits to consumers from 'shopping around'. Tables 6 and 7 show that customers on the lowest energy tariffs are materially better off in relation to the proportion of household income being spent on energy. That said, even when on the cheapest possible electricity tariff, affordability remains a significant issue for some vulnerable consumers largely because of income inadequacy.

To improve outcomes for these households, policy makers should consider the merits of regulating the cessation of credit checking as a means to restrict consumers accessing all energy offers in the market. As electricity is an essential service, all consumers have an entitlement to a retail energy product. A poor credit history can result in customers only being offered higher priced products in order for the retailer to mitigate the risk of non-payment, or, to deter the customer from accepting the contract. This practice decreases the capability of lower income households to adequately engage in the energy market. Providing low income earners access to all energy products and services, despite their credit history, would reduce the cost of energy and increase affordability and likely payment of the energy account.

Our analysis demonstrates the relationship between energy usage and the proportion of income spent on energy. The 'family formation' demographic identified by Simshauser and Nelson

\footnotetext{
${ }^{11}$ See http://www.environment.gov.au/minister/frydenberg/media-releases/mr20171218a.html (Accessed online 19 January 2018) for further information. 
(2014) aligns with our application of energy spend to the Saunders and Bedford (2017)

methodology. Based upon this finding, ongoing efforts to reform jurisdictional concession frameworks should continue with a strong focus on ensuring energy rebates are applied as a percentage of a household's energy bill, rather than as a fixed dollar amount. This would allow jurisdictional concessions budgets to be allocated in a way that better reflects the needs of different concession holders and recognises that some low-income households are better able to control energy costs, whether due to household composition and size or homeownership status which allows energy efficiency improvements to be made their dwelling.

Victoria is currently unique among Australian states in that its energy rebates are applied as a percentage (currently 17.5\%) of the household energy bill. This has been commended by consumer advocacy bodies ${ }^{12}$ both because of its durability (in effect automatically 'indexing' to changing energy costs) and because it recognises that low-income, high-consumption households are likely to be more vulnerable to energy bill stress and may potentially be restricted in their ability to reduce ongoing energy consumption. It thus automatically moderates the support provided according to the need of the household.

In other Australian jurisdictions, energy rebates tend to be applied as a lump sum amount either on an annual basis or apportioned across the customer's billing cycle. In some cases the rebates are designated as applying to either electricity or gas and in others are applied as a single 'utilities concession'. This has non-trivial implications for the relative support provided to electricity-only versus dual-fuel households. While this approach goes some way to assisting with the payment of an energy bill, it falls short of the Victorian 'percentage-based' approach in ensuring that those

\footnotetext{
12 See for example http://www.acoss.org.au/wp-content/uploads/2017/07/ACOSS_BSL_TCI_Empowering-households.pdf. Accessed online on 19 January 2018. 
who are most vulnerable from a consumption and family cohort perspective receive the most assistance. $^{13}$

\subsection{Income adequacy}

It is demonstrable from our analysis that Australia needs to urgently review the income adequacy of low-paid and unemployed households. Recall from Table 7 that a four person household dependent upon unemployment payments spends nearly seven percent of their income on electricity even when benefiting from the lowest tariff in the market. ${ }^{14}$ The 'social safety net' income should reflect a level of household earnings that is sufficient to allow low-income and unemployed households to maintain a standard of living in line with Australian community standards. There appears to be merit in pursuing an annual review mechanism for determining the adequacy of income support payments, which is independent of government and pegged to an objective measure such as a household budget standard, as recommended by Saunders and Bedford (2017). ${ }^{15}$ Without this protection, even the most well designed energy rebate frameworks will be undermined. Income support and supplementary concessions and rebates need to be viewed as a composite since a financially strained household must determine how it apportions and prioritises all of its necessary expenditure and not one item in isolation of the others.

\subsection{Consumption policy measures}

There is a strong case for expanding policy measures relating to energy efficiency in low-income homes and public housing. Our analysis shows that customers in hardship have significantly

\footnotetext{
${ }^{13}$ Howe (2018) discusses that much of the original discussion about universal basic incomes in Australia in the 1970s acknowledged that the 'large family' required additional support.

${ }^{14}$ It is worth noting that this represents the average household in this situation. There will be households that use materially more energy and therefore would be spending much more than $7 \%$ of their income on electricity.

${ }^{15}$ There is some commentary in the Australian policy debate about shifting the minimum wage to reflect a 'living wage'. We do not necessarily agree with this approach as raising labour costs may reduce employment. However, in our view there is a role for government to ensure supplementary income provided through government payments to households ensures all households are able to maintain a standard of living commensurate with Australian community expectations.
} 
higher than average consumption. There is little doubt that this is due to upfront capital barriers, the split-incentive problem and comparatively shorter housing tenures (see Section 4.4). Our recommendation builds on the strong work of Orton et al (2017) in the Australian context and finds support through international analyses such as Bird and Hernandez (2012) ${ }^{16}$, Podgornik et al (2016), and Vassileva and Campillo (2014). There is also strong evidence about the benefits of continuing to implement measures related to improving the efficiency of appliances (see Bansal et al, 2011).

\subsection{Improvements to housing tenure}

The energy efficiency rating of a home strongly influences household energy consumption. As such, there is a need to have continued focus on building standards to ensure the most optimal thermal efficiency design (Crawford et al, 2016). However, the split-incentive problem will continue to be an issue for low-income and public housing tenants (see Urmee et al, 2012, as an example of research in this area). A key relatively unexplored area of policy is potential amendments to tenancy laws to allow renters to exert greater control over their household energy costs and improve the accessibility of energy efficiency improvements (see Easthope, 2014, for recommendations in this regard). Reforms would usefully include greater security and length of rental tenure, thereby improving the economics of investments such as solar PV and efficient hot water systems. Governments could also consider tax regimes and ensuring there is an incentive for landlords to implement capital upgrades for energy efficiency purposes.

\footnotetext{
${ }^{16}$ For example, this study found that the split-incentive problem effects $1.89 \%$ of all United States' energy use. If effectively addressed, it would create a range of savings between 4 and 11 billion dollars per year for many of the nation's poorest residents. 


\section{Concluding remarks}

The price of electricity has risen significantly in Australia over the past decade. Australians have gone from paying among the lowest electricity prices in the world to among the highest. This has resulted in intense inquiry into the efficiency and fairness of the retail market for electricity. Over time, policy makers will need to continue to focus on electricity market dynamics and fundamentals. But the question of energy affordability cannot be limited just to a consideration of price. The issues relating to income adequacy need to be considered alongside broader living costs to determine if an adequate standard of living, that includes access to essential services such as energy, can be maintained. It is in Australian society's broader interest to address these issues as growing inequality and reduced social cohesion act to constrain economic growth and prosperity. 


\section{References}

Australian Bureau of Statistics: ABS. (2017), Household Expenditure Survey, Australia: Summary of Results, Available at: http://abs.gov.au/AUSSTATS/abs@.nsf/Lookup/6530.0Main+Features1201516? OpenDocument, Accessed online on 2 February 2018.

Australian Bureau of Statistics: ABS. (2016), ABS, Survey of Income and Housing (Housing Occupancy and Costs), Available at: http://www.abs.gov.au/ausstats/abs(a.nsf/mf/4130.0, Accessed online on 1 February 2018.

Australian Competition and Consumer Commission: ACCC. (2017), ACCC Retail Electricity Pricing Inquiry: Preliminary Report, ACCC Publication, Canberra.

Australian Council of Social Services: ACOSS. (2015), Inequality in Australia, ACOSS Publication, Canberra.

Australian Council of Social Services: ACOSS. (2016), Poverty in Australia, ACOSS Publication, Canberra.

Bansal, P. Vineyard, W. and Abdelaziz, O. (2011), 'Advances in household appliances - a review’, Applied Thermal Engineering, Vol. 31, No. 17, pp. 3748-3760.

Biddle, N. and Montaigne, M. (2017), 'Income inequality in Australia - decomposing by City and Suburb', Economic Papers, Vol. 36, No. 4, pp. 367-379.

Bird, S. and Hernandez, D. (2012), 'Policy options for the split incentive: Increasing energy efficiency for low-income renters', Energy Policy, Vol. 48, pp. 506-514.

Bouzarovski, S. (2014), 'Energy Poverty in the European Union: landscapes of vulnerability', Wiley Interdisciplinary Reviews: Energy and Environment, Vol 3, No. 3, pp. 276-289.

Brunner, K. Spitzer, M. and Christanel, A. (2012), 'Experiencing fuel poverty. Coping strategies of low-income households in Vienna/Austria', Energy Policy, Vol 49, pp. 53-59.

Committee for Economic Development of Australia: CEDA. (2017), Housing Australia, CEDA Publication, Melbourne.

Chester, L. and Morris, A. (2012), 'A new form of energy poverty is the hallmark of liberalised electricity sectors', Australian Journal of Social Issues, Vol. 46, No. 4, pp. 435-459.

Chester, L. (2014), 'Energy Impoverishment: Addressing Capitalism's New Driver of Inequality', Journal of Economic Issues, Vol 48, No. 2, pp. 395-403.

Chester, L. (2015), 'The privatisation of Australian electricity: claims, myths and facts', The Economic and Labour Relations Review, Vol. 26, No. 2, pp. 218-240.

Crawford, R. Bartak, A. and Jensen, C. (2016), 'Evaluating the life cycle energy benefits of energy efficiency regulations for buildings', Renewable and Sustainable Energy Reviews, Vol. 63 , pp. 435-451. 
Department of Environment, Land, Water and Planning: DELWP. (2017), Review of electricity and gas retail markets in Victoria, Victorian Government Publication, Melbourne.

Dollman, R. Kaplan, G. La Cava, G. and Stone, T. (2015), Household Economic Inequality in Australia, RBA Research Discussion Paper, Sydney.

Easthope, H. (2014), 'Making a rental property a home', Housing Studies, Vol. 29, No. 5, pp. 579-596.

Fenna, A. and Tapper, A. (2015), 'Economic inequality in Australia: A reassessment', Australian Journal of Political Science, Vol. 50, No.3, pp. 393-411.

Fletcher, M. and Guttmann, B. (2103), Income Inequality in Australia, Economic Roundup, No. 2.

Frontier Economics. (2016), Determinants of household energy consumption, A report prepared for the Independent Pricing \& Regulatory Tribunal, Frontier Economics Publication, Sydney.

Grattan Institute. (2017), Price shock: Is the retail electricity market failing consumers?, Grattan Institute Publication, Melbourne.

Heflin, C. London, A. and Scott, E. (2011), 'Mitigating Material Hardship: The Strategies LowIncome Families Employ to Reduce the Consequences of Poverty', Social Inquiry, Vol 81, No. 2, pp. 232-246.

Howe, B. (2018), 'Australians support universal health care, so why not a universal basic income?', The Conversation, February 13.

Independent Pricing and Regulatory Tribunal: IPART. (2015), IPART 2015 household survey Payment difficulties, IPART Publication, Sydney.

Klapdor, M. (2014), Adequacy of Income Support Payments, Australian Parliamentary Library Publication, Canberra.

Lee, D. and Son, J. (2016), 'Economic Growth and Income Inequality: Evidence from Dynamic Panel Investigation', Global Economic Review: Perspectives on East Asian Economies and Industries, Vol 45, No. 4, pp. 331-358.

McLachlan, R. Gilfillan, G. and Gordon, J. (2013), Deep and Persistent Disadvantage in Australia, Productivity Commission Staff Working Paper, Canberra.

Middlemiss, L. and Gillard, R. (2015), 'Fuel poverty from the bottom-up: Characterising household energy vulnerability through the lived experiences of the fuel poor', Energy Research \& Social Science, Vol 6, pp. 146-154.

Nelson, T. McCracken-Hewson, E. Whish-Wilson, P. and Bashir, S. (2018), 'Price dispersion in Australian retail electricity markets', Energy Economics, Vol. 70, pp.158-169.

New South Wales Council of Social Service: NCOSS. (2017), Turning Off The Lights, The cost of living in NSW, NCOSS Publication, Sydney.

Organisation for Economic Cooperation and Development: OECD. (2015), In It Together: Why Less Inequality Benefits All, OECD Publication, Paris. 
Orton, F. and Nelson, T. (2015) 'Relief in sight: Why residential electricity costs in Eastern Australia may fall between 2015 and 2020', Economic Analysis and Policy, Vol. 48, pp. 57-70.

Orton, F. Nelson, T. Pierce, M. and Chappel, T. (2017), 'Access Rights and Consumer Protections in a Distributed Energy System', in Innovation and Disruption at the Grid's Edge, Elsevier.

Podgornik, A. Sucic, B. and Blazic, B. (2016), 'Effects of customised consumption feedback on energy efficient behaviour in low-income households', Journal of Cleaner Production, Vol. 130, pp. 25-34.

Queensland Council of Social Services: QCOSS. (2016), Cost of living: age pensioner households, QCOSS Publication, Brisbane.

Queensland Council of Social Services: QCOSS. (2017), Choice and Control? The experiences of renters in the energy market, QCOSS Publication, Brisbane.

Saunders, P. and Bedford, M. (2017), 'New Minimum Income for Healthy Living Budget Standards for Low-Paid and Unemployed Australians', UNSW Social Policy Research Centre Report 11.

Simshauser, P. and Nelson, T. (2014), 'The Consequences of Retail Electricity Price Rises: Rethinking Customer Hardship', The Australian Economic Review, Vol 47, Issue 1, pp. 13-43

Simshauser, P. Nelson, T. and Doan, T. (2011), 'The Boomerang Paradox Part 1: how a nation's wealth is creating fuel poverty', The Electricity Journal, Vol. 24, No. 1, pp. 72-91.

Simshauser, P. and Whish-Wilson, P. (2017), 'Price discrimination in Australia's retail electricity markets: An analysis of Victoria \& Southeast Queensland', Energy Economics, Vol. 62, pp. 92103.

Urmee, T. Thoo, S. and Killick, W. (2012), 'Energy efficiency status of the community housing in Australia', Renewable and Sustainable Energy Reviews, Vol. 16, No. 4, pp. 1916-1925.

Vassileva, I. and Campillo, J. (2014), 'Increasing energy efficiency in low-income households through targeting awareness and behavioural change', Renewable Energy, Vol. 67, pp. 59-63.

Wilkins, R. (2015), 'Measuring Income Inequality in Australia', The Australian Economic Review, Vol. 48, No. 1, pp. 93-102.

Wood, G. and Ong, R. (2017), 'The Australian housing system: a quiet revolution?', The Australian Economic Review, Vol. 50, No. 2, pp. 197-204. 